\section{Effect of Ocimum gratissimum in Mouthrinses on De Novo Plaque Formation. A Randomized Clinical Trial}

\author{
Manoela Siqueira Pimenta ${ }^{1}$, Nayana Santiago Guedis Lobo ${ }^{1}$, Virna Castelo \\ Vieira ${ }^{1}$, Ângela Maria Alves da Costa², Flávio Nogueira da Costa², Sérgio \\ Luís da Silva Pereira ${ }^{1}$
}

'Dental School, UNIFOR - University of Fortaleza, Fortaleza, CE, Brazil

${ }^{2}$ School of Pharmacy, UNIFOR

- University of Fortaleza,

Fortaleza, CE, Brazil

Correspondence: Sérgio Luís da Silva Pereira, Av. Engenheiro Leal Lima Verde, 2086, Alagadiço Novo, 60830-055 Fortaleza, CE, Brasil. Tel: +55-85-3477-3201. e-mail address: luiss@unifor.br
The aim of this study was to evaluate the antiplaque effect of Ocimum gratissimum $(\mathrm{Og})$ by in vivo investigation. Fifteen healthy volunteers participated in a crossover, double-blind clinical study, using a 3-day partial-mouth plaque accumulation model. The participants abolished any method of mechanical oral hygiene and they were randomly assigned to initially use just the following mouthrinses: distilled water (DW solution), $0.12 \%$ chlorhexidine digluconate (CLX solution) or $10 \% \mathrm{Og}$ (Og solution). The plaque index (PLI) was recorded in all mandibular teeth at the end of the trial and the Kruskal-Wallis $(\alpha=0.05)$ and Mann-Whitney $(\alpha=0.05)$ tests were used to estimate the difference among groups. The clinical results showed statistically significant difference among the groups $(p<0.05)$, favoring the CLX solution and Og solution, but the first was more effective $(p<0.05)$. The mouthrinses containing $0.12 \%$ chlorhexidine digluconate and $10 \% \mathrm{Og}$ were able to inhibit plaque re-growth, however $\mathrm{Og}$ showed more limited results in comparison to $\mathrm{CLX}$.
Key Words: dental plaque, plant extracts, chlorhexidine, mouthrinses, prevention

\section{Introduction}

Regular plaque removal by effective mechanical tooth cleaning is the main goal of the prevention of gingival inflammation. However, this concept is difficult to implement by many subjects $(1,2)$ because its effectiveness is influenced by the individual's manual ability and motivation (2).

This is the reason of a great interest to research antimicrobial agents in order to avoid plaque formation and are often recommended in situations when oral hygiene is difficult, compromised or impossible (2-4). Chlorhexidine is considered the gold standard chemical agent, showing positive results, by inhibiting or delaying the bacterial proliferation (1-4). However, due to undesirable effects after prolonged use, like pigmentation and taste disturbance, various herbal agents have been researched recently, showing encouraging results (5-8).

Aromatics herbs have traditionally been used in folk medicine, showing inhibition against several groups of microorganisms $(6,9)$. Plants from Brazilian biomes have also been used as natural medicines by local populations in the treatment of several tropical diseases, including fungal and bacterial infections $(9,10)$.

Among the various available herbal agents, Ocimum gratissimum $(\mathrm{Og})$ is found in tropical regions, including Brazil, where it is popularly know as "alfavaca-cravo" (6). $\mathrm{Og}$ belongs to the group of plants known as spices (9). It is of the family Labiatea, genus Ocimum, species gratissimum and it is commonly used to treat different diseases, e.g. skin diseases and pneumonia $(9,10)$.

Laboratorial previous studies showed that $0 \mathrm{~g}$ presents antimicrobial activities, showing that this herbal agent can be effective against infectious diseases $(9,10)$. Extract of $\mathrm{Og}$ have been tested in vitro and shown to be active against S. flexineri, E. coli and Proteus mirabililis. as well as dermatophytes $(6,9,10)$. Likewise, pre-clinical studies showed that this herbal agent inhibited the growth of oral microorganisms $(11,12)$, like Streptococcus viridans and $S$. albus, showing that $0 \mathrm{~g}$ can be used as antiplaque agent. Besides, it presents antinociceptive and anti-inflammatory activities, showing that this herbal agent is effective in the treatment of acute and chronic oral diseases (10).

In a3-month previous clinical study, there were no adverse effects using $\mathrm{Og}$ as mouthwash, showing that it was well tolerated, supporting its safety for the clinical use (6). In addition, $0 \mathrm{~g}$ was effective on plaque reduction and in the treatment of gingivitis, as adjunct to mechanical plaque control, comparable to chlorhexidine digluconate. However, its effect associated to tooth brushing has not been tested.

These previous results pointed out that $\mathrm{Og}$ has potential as mouth rinse, but is this herbal agent able to avoid plaque re-growth? Up to now there is no reported controlled trial evaluating the efficacy of $\mathrm{Og}$ on this issue. Therefore, the aim of the present study was to assess the action of this herbal agent on de novo plaque formation, compared to 
digluconate chlorhexidine.

\section{Material and Methods}

\section{Subjects}

Fifteen dental students from the University of Fortaleza ( 7 female and 8 male, aged 18 to 24 years) were enrolled in this study. All subjects had at least 24 natural teeth, showed no signs of periodontitis, had no caries or extensive dental restorations and did not undergo any systemic antibiotic treatment during past 6 months. Participants with medical disorders, smokers and pregnant women were excluded from the trial (Table 1). All students were informed about the nature of the study and signed an informed consent form in compliance with the guidelines of the Brazilian Health Council and Helsinki Declaration of 1975. The research protocol was approved by the institutional Ethics Committee (Process Number 329/2010).

Due to the scarcity of previous studies with the same herbal product $(\mathrm{Og})$, a proper sample-size calculation could not be made. Based on similar studies, a sample size of 15 patients was considered adequate. After the study, a power calculation was performed, showing an $85 \%$ power to detect a difference of 0.50 in plaque index among groups, considering a standard deviation of 0.5 (13).

\section{Essential Oil Extraction, Preparation and Composition}

Og essential oil was prepared from stem barks samples collected from the medicinal herb Garden at the University of Fortaleza, CE, Brazil. Essential oil was extracted using a modified Clevenger apparatus by the hydrodistillation technique. The volume of essential oil obtained was measured and then it was stored in hermetically sealed glass receptacles with rubber stoppers, covered with aluminum foil to protect the contents from light and kept under refrigeration at $8{ }^{\circ} \mathrm{C}$ until use. The chemical composition was determined by High Performance Thin Layer Chromatography (HPTLC). The major constituents of the essential oil were thymol and eugenol, respectively.

\section{Preparation of the Mouthrinses}

Initially $1 \mathrm{~mL}$ of essential oil was diluted in $9 \mathrm{~mL}$ of distilled water (1:9), preparing a 10\% mixture (v/v) $(0 \mathrm{~g}$ solution). A mouth rinse containing only distilled water (DWsolution) and other containing $0.12 \%$ chlorhexidine digluconate (CLX solution) were formulated too. In all groups, a very small amount of menthol (flavoring), color and conserving agent were added.

\section{Products}

All mouthrinses were formulated and packed into bottle in the Pharmaceutics' Laboratory at the University of Fortaleza. The bottles were previously coded to warrant that neither the examiner nor the participants knew their content, which was revealed by the pharmacist only after the study was completed. All students used all mouthrinses in alternate periods, according to a crossover study.

\section{Clinical Design}

This study was a randomized, double-blind comparison of 3 cross-over groups of dental students performed in 3 experimental phases of 3 days each with a 1-month washout interval, until all subjects had rinsed with each formulation. To standardize the groups, the participants were submitted to a meticulous evaluation (pre-experimental phase) to score the Plaque Index (PLI) (14) of each tooth. All teeth of each subject were polished and flossed by the examiner to eliminate dental plaque remnants. The importance of oral hygiene was strongly reinforced.

Thirty days after the initial phase, the volunteers were randomly assigned to 3 groups by random allocation using a computer-generated random table made by a person not participating in the study and the experimental phase began. On day 0 of both experimental periods, PLI was recorded. During each 3-day experimental period, the participants were instructed to abstain from all forms of mechanical oral hygiene. A bottle containing $100 \mathrm{~mL}$ mouth rinse was given to all students and they were instructed to rinse 10 $\mathrm{mL}$ for $60 \mathrm{~s}$, twice daily (in the morning and in the evening), and then spit it out. In addition to verbal instructions, the students received written recommendations to follow at home. On the last day of each period (3rd day), the PLI was recorded and the teeth were polished with pumice (Fig. 1).

\section{Clinical Assessment}

A single examiner recorded the PLI on the buccal and lingual surfaces of the experimental mandibular teeth. The plaque was disclosed using a 1\% erythrosine solution and the values of two sites of each tooth were recorded to obtain the PLI means. Then, the means for all experimental

Table 1. Patient characteristics at the baseline

\begin{tabular}{|c|c|}
\hline Number of patients & $\mathrm{N}=15$ \\
\hline Sex & $\begin{array}{l}8 \text { males anda } \\
7 \text { females }\end{array}$ \\
\hline Age & $\begin{array}{l}18-24 \text { (mean age } \\
20,8 \pm 2.1 \text { years) }\end{array}$ \\
\hline Number of teeth & $24 \pm 2.4$ teeth \\
\hline $\begin{array}{l}\text { Periodontitis, caries and/ } \\
\text { or extensive restorations }\end{array}$ & No \\
\hline Systemic antibiotic treatment (past 6 months) & No \\
\hline $\begin{array}{l}\text { Systemic healthy and no smokers } \\
\text { and no pregnant women }\end{array}$ & Yes \\
\hline
\end{tabular}


teeth were calculated to determine the mean index of each volunteer. Intra-examiner agreement was obtained by repeating the measurements in 10 patients, obtaining a 0.79 Kappa coefficient. Mouthrinses were evaluated for side effects by subjective criteria, including taste disturbance, burning sensation, dryness/soreness, pruritis/itchiness. Visual inspection was made to observe staining and soft tissue alteration.

\section{Statistical Analysis}

The Kruskal-Wallis and Mann-Whitney $(\alpha=0.05)$ tests were used to evaluate the difference among groups on day $3(p<0.05)$. However, for illustration, the results are showed as mean and standard deviation.

\section{Results}

All subjects completed the experimental phase. The mouthrinses had good acceptance and did not show significant adverse events, such as abscesses, ulcerations or allergic reactions. Only in the CLX group, three patients related mild burning sensation.

At the 3rd day, there was plaque formation in all groups, but the differences among them were statistically significant $(p<0.05)$, favoring CLX and $0 g$ solutions. However, after comparing these two solutions, there was a statistically significant difference favoring CLX solution $(p<0.05)$ (Table 2).

Comparing means for each dental surface, there was a statistically significant difference in the PLI index for all surfaces, favoring CLX and $0 \mathrm{~g}$ solutions $(\mathrm{p}<0.05)$. However, comparing these two solutions, there was a statistically significant difference favoring CLX solution $(\mathrm{p}<0.05)$ (Table 3).

Table 2. Plaque index (PLI) means and standard deviation (sd) on day 3 for the positive control (CLX solution), test (Og solution) and negative control (DW solution) groups.

\begin{tabular}{llll}
\hline & CLX solution & Og solution & DW solution \\
\hline Mean $\pm \mathrm{sd}$ & $2,38 \pm 0,49 \mathrm{a}$ & $2,85 \pm 0,44 \mathrm{~b}$ & $3,27 \pm 0,45 \mathrm{c}$ \\
\hline
\end{tabular}

Means followed by different letters differ statistically $(\mathrm{p}<0.05)$.

Table 3. Plaque index (PLI) means and standard deviation (sd), by dental surface, on day 3 for the positive control (CLX solution), test (Og solution) and negative control (DW solution) groups.

\begin{tabular}{llll}
\hline & CLX solution & Og solution & DW solution \\
\hline Buccal & $2,30 \pm 0,57 \mathrm{a}$ & $2,92 \pm 0,70 \mathrm{~b}$ & $3,50 \pm 0,73 \mathrm{c}$ \\
Lingual & $2,31 \pm 0,47 \mathrm{a}$ & $2,74 \pm 0,64 \mathrm{~b}$ & $3,15 \pm 0,59 \mathrm{c}$ \\
\hline
\end{tabular}

Means followed by different letters in a same line differ statistically $(\mathrm{p}<0.05)$.

\section{Discussion}

This paper presents the data of a short-term, crossover, de novo plaque growth study, involving the replacement of mechanical plaque control by mouth rinsing, comparing an allopathic substance with an herbal agent. This study design was based in previous works and it was chosen in order to generate the best possible clinical evidence $(2,4,8)$. It measures the plaque regrowth under the influence of test solution from a zero plaque baseline and avoids the confounding influences of tooth brushing $(15,16)$.

The purpose of the present work was to study plaque accumulation event and not gingival inflammation, in which longer periods of evaluation would be necessary, in spite of some similar studies that evaluated this aspect $(1,3)$. In this way, based on previous works, a 3-day plaque accumulation model was used $(2,4,5,15,16)$. The validity of short-term models ( 3 days or 4 days) has been extensively discussed and they are valid to investigate antiplaque effects $(7,8,15-19)$. In the present study, a negative and a positive control were used to allow the positioning of the test product between both extremes. Based in other similar studies $(2,7,8)$, distilled water was chosen as a negative

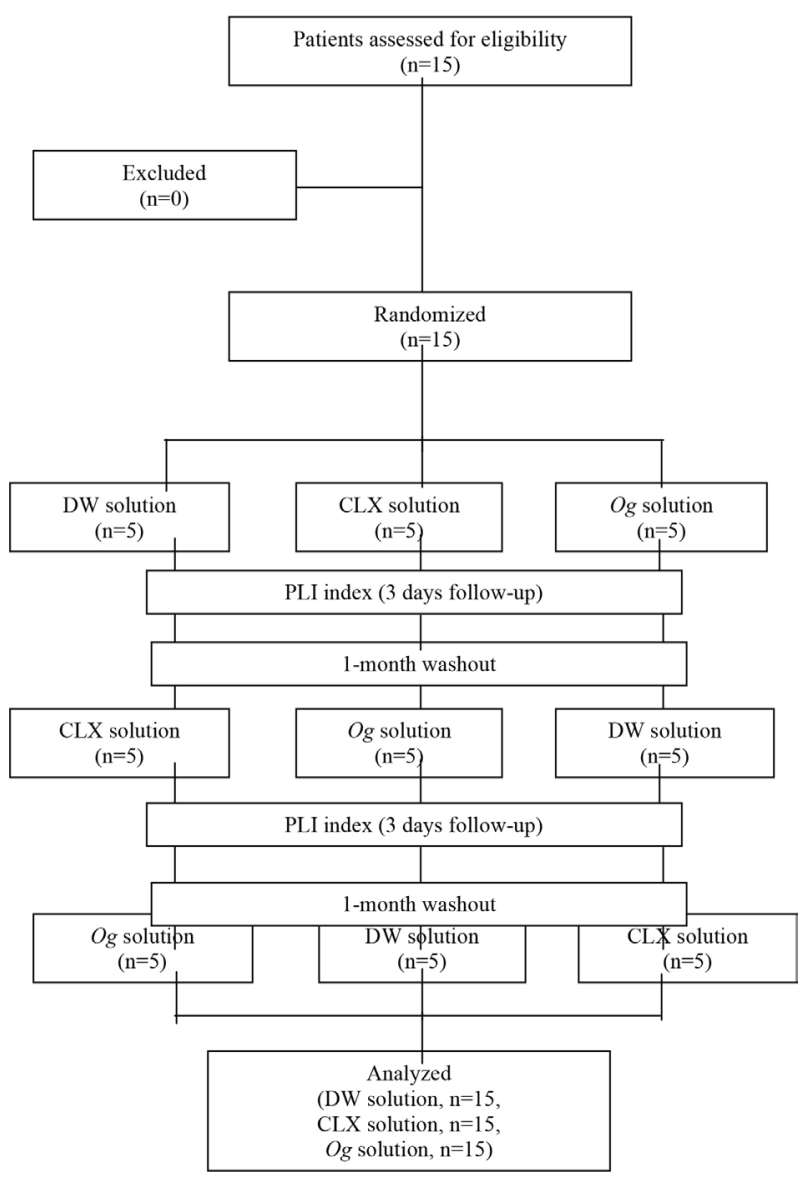

Figure 1. Flowchart for the study patients. 
control product, because its inert characteristic and it was the vehicle of the other two products.

Generally, for such model, is used a crossover approach, as in the present study (18). To avoid the carry-over effects, after each test period the subject had a washout time of one month (2), a longer period than the one often employed $(13,16-18)$, during which mechanical oral hygiene was resumed with the same fluoridated dentifrice. Then, another 3-day test period started with a new assigned product.

It is very important to note that when the chlorhexidine digluconate is included as a positive control, there is concern that the effect of this potent agent might persist for longer than the 3-day washout period. The residual effect of chlorhexidine differs from that of an inert rinse such as saline or water. Consequently, a longer washout period is preferable (19).

Periodontal condition is of foremost importance in the rate of de novo plaque formation. This aspect justifies the use of dental students that have a standard of good oral hygiene (15). Moreover, this is an interesting group for this kind of study, taking into consideration that they can be easily controlled in terms of compliance $(1,2,20)$. A point not be overlooked is the sample size of the present work, as previously explained in Material and Methods section. However, studies with similar aims have been published with sample sizes comparable to the one of this study $(2,13,20)$.

Mouthrinses vary in their constituents but are usually considerably less complex than toothpastes and they need to be stable and with an acceptable taste. This usually requires the addition of flavor, color and preservation additives (16). In the present study, this was observed so that the products had similar aspects as much possible. Quality control was also applied to the rinses following reference to the monograph in the Brazilian Pharmacopoeia, analyzing the organoleptic characteristics, density and $\mathrm{pH}$ (1.02 and 6.87 , respectively) (21). This similarity to the mouth and oral mucosa $\mathrm{pH}$ may explain, in part, the absence of adverse events after $0 \mathrm{~g}$ mouth rinse usage.

Taste acceptance is poorly discussed in the studies, since just two articles evaluated this aspect by a questionnaire to assess the patient's attitudes and preferences regarding the products used $(7,15)$. Although the products had been coded, the present study and studies mentioned above did not evaluate whether the participants could perceive which solution he/she was using during the clinical trial, mainly chlorhexidine which has a quite characteristic taste. Perhaps, this could be a major limitation of this type of study, in which chlorhexidine is used as positive control $(2,7,8,17,20)$.

Among a variety of antiseptic agents, chlorhexidine digluconate has been used and tested for many years and its long-term efficacy and safety has been confirmed by several in vivo studies $(1-3,7,8,17,20)$. Unfortunately, chlorhexidine has some disadvantages, like discoloration in proximal areas, tongue and a reversible effect on the taste (3-5). In the present study these aspects were not observed, probably due the short-term characteristic of the present study, likewise the other works $(2,7,8.17,20)$.

Chlorhexidine mouth rinse is considered as the gold standard for oral antiseptics and its effectiveness as antiplaque agent was observed in the present and other studies $(2,4,7,15,17)$. In terms of plaque accumulation, several studies found no difference between $0.12 \%$ or $0.20 \%$ chlorhexidine concentrations $(17,20)$. In the present work was used $0.12 \%$, which is generally used in commercial mouthrinses. Lower concentrations of chlorhexidine should be prescribed since higher concentrations do not seem to generate lower plaque scores $(15,17,20)$.

In this study, the Quigley and Hein plaque index (13) was used due its sensitivity to detect small deposits of plaque $(2,20,22,23)$. However, the cut-off between the scores can be difficult to assess and could interfere in the results, so calibration of examiners was performed to solve this problem, assuring the confidence of results $(2,20)$. Other studies recorded plaque accumulation in full mouth, using a similar plaque index $(1,5,6)$. This fact could explain the differences of values on plaque accumulation in comparison to present work.

In recent times, reports of a number of medicinal herbs used in the prevention of gingivitis have been published worldwide, presenting limited $(23,24)$ and encouraging results $(2,5,7)$. Despite its commercial use in pharmaceutical industries, there is lack of data to support the antiplaque claims about $\mathrm{Og}$. The absence of adverse effects from this herbal agent in the present study showed that it was well tolerated, supporting safety for the clinical use. This aspect was observed in a previous 3-month study (6).

To the best of the authors' knowledge, the present work is the first to evaluate the effect of a mouth rinse containing $\mathrm{Og}$ on de novo plaque formation. The results showed that even though the herbal formulation was able to inhibit plaque re-growth it was not as efficient as the gold standard antiplaque mouth rinse. Because of new formulation of the used mouthwash, direct comparisons of the results are limited.

In a single recent study, mouthwash containing $\mathrm{Og}$ reduced the plaque similarly to chlorhexidine (6). In this study the tooth brushing was associated to mouth rinsing, which could mask the real effect of the mouthwash. Besides, it seems that the substantivity of the $0 \mathrm{~g}$ is not similar to chlorhexidine, since in the present study the interval was 12 $\mathrm{h}$ and in that work mouth rinsing was performed $3 \mathrm{x} /$ day (6).

In in vitro studies, $\mathrm{Og}$ inhibited the growth of oral microorganisms $(11,12)$, which allows to deduce that this 
phytotherapeutic may be used as antiplaque agent. When prepared as component of mouthrinses, Og completely inhibited the growth of Streptococcus viridans and S. albus, implicated in gingivitis and dental caries, respectively (11). Although those are in vitro studies and the likelihood of changes in a patient's microflora activity cannot be ruled out as it function in vivo, the antimicrobial action was confirmed in the present clinical study.

Volatile oils constitute a group of plants' secondary metabolites preferably obtained through hydro distillation and some have potent antimicrobial effects (11). The major constituents found in $\mathrm{Og}$ and also known for their antimicrobial activity are eugenol and thymol (6). The action mechanism of eugenol occurs in plasmatic membrane level and is attributed to cellular lipids alterations, loss of intracellular material and inhibition of nucleic acid synthesis (25). Antimicrobial action from thymol is due to its phenolic character, which may cause membranedisturbing activities (25). These antimicrobial actions may explain the antiplaque effect of $\mathrm{Og}$ and they agree with other works in which different herbal agents with similar constituents have been investigated $(2,5,7,8)$.

Based on the obtained results, it can be stated that this new herbal product has a promising plaque inhibitory potential. Further studies with a larger sample to increase the external validity are required in order to evaluate its substantivity in the oral cavity, as well as microbiological parameters essential to establish the true effectiveness of this mouth rinse and its position among other similar products.

\section{Resumo}

0 objetivo do presente estudo foi avaliar clinicamente em humanos o efeito antiplaca de Ocimum gratissimum $(0 \mathrm{~g})$. Quinze adultos saudáveis participaram deste estudo cruzado, duplo-cego, por meio de um modelo de acúmulo de placa parcial de 3 dias. Os voluntários aboliram qualquer método mecânico de higiene oral e foram inicialmente designados para usar os seguintes enxaguatórios bucais: água destilada (solução $A D$ ), digluconato de clorexidina a $0,12 \%$ (solução CLX) ou $10 \% \mathrm{Og}$ (solução $0 \mathrm{~g}$ ). 0 indice de placa (IPL) foi registrado em todos os dentes inferiores no final do experimento e os testes estatísticos Kruskal-Wallis $(\alpha=0,05)$ e Mann-Whitney $(\alpha=0,05)$ foram utilizados para estimar a diferença entre os grupos. Os resultados clinicos demonstraram diferença estatisticamente significante entre os três grupos $(p<0,05)$, favorecendo os grupos CLX e Og; entretanto o grupo CLX foi mais efetivo que o grupo $0 \mathrm{~g}(p<0,05)$. Os enxaguatórios bucais contendo digluconato de clorexidina e $\mathrm{Og}$ a $10 \%$ foram capazes de reduzir a formação de nova placa bacteriana, mas $0 \mathrm{~g}$ mostrou resultados mais limitados em comparação ao digluconato de clorexidina.

\section{References}

1. Lorenz K, Bruhn G, Heumann C, Netuschil L, Brecx M, Hoffmann T. Effect of two new chlorhexidine mouthrinses on the development of dental plaque, gingivitis and discolouration. A randomized, investigator-blind, placebo-controlled, 3-week experimental gingivitis study. J Clin Periodontol 2006;33:561-567.

2. Rodrigues ISC. Oliveira DB, Menezes PCB, Costa FN, Carlos MXC,
Pereira SLS. Effect of Lippia sidoides in mouthrinses on de novo plaque formation: A double-blind study in humans. Indian J Dent Res 2013;31:533-536.

3. Graziani F, Gabriele M, D'Aiuto F, Suvan J, Tonelli M, Cei S. Dental plaque, gingival inflammation and tooth-discolouration with different commercial-formulations of $0.2 \%$ chlorhexidine rinse: a doubleblind randomized controlled clinical trial. Oral Health Prev Dent 2015;13:101-111.

4. van Der Weijden, FA., van Der Sluijs E, Ciancio SG, Slot DE. Can chemical mouthwash agents achieve plaque/gingivitis control? Dent Clin North Am 2015;59:799-829.

5. Botelho MA, Bezerra Filho JG, Correa LL, Fonseca SGC, Montenegro D, Gapski R. Effect of a novel essential oil mouth rinse without alcohol on gingivitis: a double-blinded randomized controlled trial. J Appl Oral Sci 2007;15:175-180.

6. da Silva Pereira SLS, de Oliveira JWG, Ângelo KKSV, da Costa AMA, Costa FN. Clinical effect of a mouth rinse containing Ocimum gratissimum on plaque and gingivitis control. J Contemp Dent Pract 2011;12:350-355.

7. Chhina S, Singh A, Menon I, Singh R, Sharma A, Aggarwal V. A randomized clinical study for comparative evaluation of Aloe vera and $0.2 \%$ chlorhexidine gluconate mouthwash efficacy on de novo plaque formation. J Int Soc Prev Community Dent 2016;6:251-255.

8. Singh A, Daing A, Dixit J. The effect of herbal, essential oil and chlorexidine mouthrinse on de novo plaque formation. Int J Dent Hygiene 2013;11:48-52.

9. Nakamura CV, Nakamura TU, Bando E, Melo AFN, Cortez DAG, Filho BPD. Antibacterial activity of Ocimum gratissimum L. essential oil. Mem Inst Oswaldo Cruz 1999;94:675-678.

10. Tanko Y, Magaji GM, Yerima M, Magaji RA, Mohammed A. Antinociceptive and anti-inflammatory activities of aqueous leaves extract of Ocimum gratissimum (Labiate) in rodents. Afr J Trad CAM 2008;5:141-146.

11. Ahonkai I, Ayinde BA, Edogun O, Uhuwmangho MU. Antimicrobial activities of the volatile oils of Ocimum bacilicum L. and Ocimum gratissimum L. (Lamiaceae) against some aerobic dental isolates. Pak J Pharm Sci 2009;22:405-409.

12. Thaweboon $\mathrm{S}$, Thaweboon B. In vitro antimicrobial activity of Ocimum americanum L. essential oil against oral microorganisms. Southeast Asian J Trop Med Public Health. 2009;40:1025-1033.

13. Garcia V, Rioboo M, Serrano J, O' Connor A, Herrera J, Sanz M. Plaque inhibitory effect of a $0.05 \%$ cetyl-pyridinium chloride mouth rinse in a 4-day non-brushing model. Int J Dent Hygiene 2011;9:266-273.

14. Quigley GA, Hein JW. Comparative cleansing efficiency of manual and power brushing. J Am Dent Assoc 1962;65:2-29.

15. Slot DE, Rosema NAM, Hennequin-Hoenderdos NL, Versteeg PA, van der Velden $\mathrm{U}$. The effect of $1 \%$ chlorhexidine gel and $0.12 \%$ dentifrice gel on plaque accumulation: a 3-day non-brushing model. Int J Dent Hygiene 2010;8:294-300.

16. Verstteg PA, Rosema NAM, Hoenderdos NL, Slot DE, Van der Wijden $\mathrm{GA}$. The plaque inhibitory effect of a CPC mouth rinse in a 3-day plaque accumulation model - a cross-over study. Int J Dent Hygiene 2010;8:269-275.

17. Pilloni A, Zeza B, Mongardini C, Dominici F, Cassini MA, Polimeni A. A preliminar comparison of the effect of $0.3 \%$ versus $0.2 \%$ chlorhexidine mouth rinse on de novo plaque formation: a monocentre randomized double-blind crossover trial. Int J Dent Hygiene 2013;11:198-202.

18. De Siena F, Del Fabbro M, Corbella S, Taschieri S, Weinstein R. Evaluation of chlorhexidine $0.05 \%$ with the adjunct of fluoride $0.05 \%$ in the inhibition of plaque formation: a double blind, crossover, plaque regrowth study. Int J Dent Hygiene 2013;11:186-190.

19. Newcombe RG, Addy M, McKewon. Residual effect of chlorhexidine gluconate in 4-day plaque regrowth cross-over trials, and its implications for study design. J Period Res 1995;30:319-324.

20. Franco Neto CA, Parolo CCF, Rösing CK, Maltz M. Comparative analysis of the effect of two chlorhexidine mouthrinses on plaque accumulation and gingival bleeding. Braz Oral Res 2008;22:139-144.

21. Brasil. Farmacopeia Brasileira. 2a ed. Brasília: Anvisa; 2010.

22. Rodrigues ISC, Tavares VN, Pereira SLS, Costa FN. Antiplaque and antigingivitis effect of Lippia sidoides. A double-blind clinical study 
in humans. J Appl Oral Sci 2009;17:404-407.

23. Pereira SLS, Barros CS, Salgado THY, Filho VPP, Costa FN. Limited benefit of Copaifera oil on gingivits progression in humans. J Contemp Dent Pract 2010;11:57-64.

24. Salgado ADY, Maia JL, Pereira SLS. Antiplaque and antigingivitis effects of a gel containing Punica granatum Linn extract. A double-blind clinical study in humans. J Appl Oral Sci 2006;14:162-166.

25. Helander IM, Alakomi HL, Latva-Kala K, Mattila-Sandholm T, Pol I,
Smid EJ, et al.. Characterization of the action of selected essential oil components on Gram-negative bacteria. J Agric Food Chem 1998;46:3590-3595

Received July 1, 2016 Accepted October 13, 2016 